\title{
Microbial Co-infections in Covid Patients: A Mini Review
}

\author{
Rajkumar Bhosale, Sasidharan Sakkan, and Sriram Padmanabhan
}

\section{ABSTRACT}

In this review, we highlight the complications of COVID-19 affected patients due to microbial infections, which increase the severity of the disease. Nearly $50 \%$ of COVID-19 affected patients among non-survivors were either coinfected with bacterial, fungal, or viral pathogens. During ongoing COVID19 pandemic, it has been a challenge for developing and under developing countries to identify co-infections in patients due to limited healthcare facilities and high cost for the diagnostic tests. Since several microbial coinfections are associated with COVID-19, there is need to diagnose such coinfections in early stage so that required control measures would be taken to avoid the further health risks. People with severe COVID-19, COVID-19 patients in intensive care units (ICU), are susceptible to bacterial and fungal infections. Bacterial pathogens, representing less than $14 \%$ of patients with reported infections include Mycoplasma pneumoniae, Haemophilus influenzae and Pseudomonas aeruginosa while fungal sps include Aspergillus, Candida auris, black fungus etc that invade the brain or cause patients to lose vision. The unregulated and inappropriate use of antibiotics, antimicrobial drugs and alcohol based hand sanitizers may enhance the evolution of AMR phenotypes among infectious pathogens.

Published Online: October 10, 2021

ISSN: 2684-5199

DOI: $10.24018 /$ ejbio.2021.2.5.275

Rajkumar Bhosale

Herbal Division, Sava Healthcare Limited, Research Center, Chinchwad, Pune, India. Sasidharan Sakkan

QC, Microbiology Division, Sava Healthcare Limited, KIADB Industrial Area, Malur, India.

Sriram Padmanabhan*

(e-mail: sriram.p ${ }^{\circledR}$ savaglobal.com)

*Corresponding Author

Keywords: Bacteria, COVID-19, variants, mutants, EDTA, antibiotic resistance.

\section{INTRODUCTION}

The Coronavirus disease-2019 (COVID-19) is caused by a zoonotic virus, Severe Acute Respiratory Syndrome Coronavirus-2 (SARS-CoV-2) and it is the most severe pandemic of $21^{\text {st }}$ century [1]. The first case of COVID-19 was reported in December 2019 in Wuhan region of China [2]. Due to stronger transmission capacity of SARS-CoV-2 [3]; within a year, the epidemic has affected more than 210 countries reporting over 138 million positive cases and 2.9 million deaths worldwide and has become a global health concern (Fig. 1).

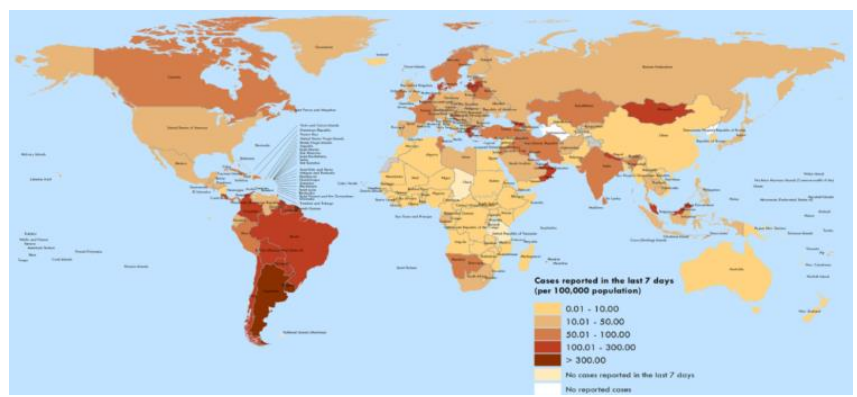

Fig. 1. Current status of COVID-19 worldwide. (Data Source: Weekly epidemiological update given by World Health Organization on 01 June 2021).

The genetic variations in SARS-CoV-2 and microbial coinfections in COVID-19 patients are the two major obstacles in preventing transmission of the disease and to reduce the fatality rate. Respiratory bacterial and viral coinfections, predominantly found in patients hospitalized for SARS-CoV-2 infections; are mainly categorized into community acquired and hospital acquired coinfections [4] In some cases, fungal infections are also associated with COVID-19 patients. The increased severity of COVID-19 disease can also depend upon the associated microbial coinfections. The information regarding antimicrobial resistant (AMR) pattern of such microbial strains would serve as a guiding tool for physicians for effective treatment SARSCoV-2 affected patients and reduce issues involved in the management of COVID-19 pandemic (Fig. 2).

\section{GLOBAL VARIANTS OF SARS-COV-2}

Mutations in SARS-CoV-2 results in the emergence of new global variants of concern such as B.1.1.7 PANGO lineage in United Kingdom, B.1.351 PANGO lineage in South Africa and B.1.1.28.1 PANGO lineage in Brazil and Japan. The variant B.1.1.7 was first reported in United Kingdom on 20 September 2020 which is most dominant lineage among all the variants due to high rate of mutation in Non-structural Protein-6 (NSP-6). The NSP-6 is responsible for attachment of virus to Angiotensin Converting Enzyme-2 (ACE-2) receptor present on the surface of human epithelial cells located in the lungs, arteries, heart, kidney, and intestines [5]. 


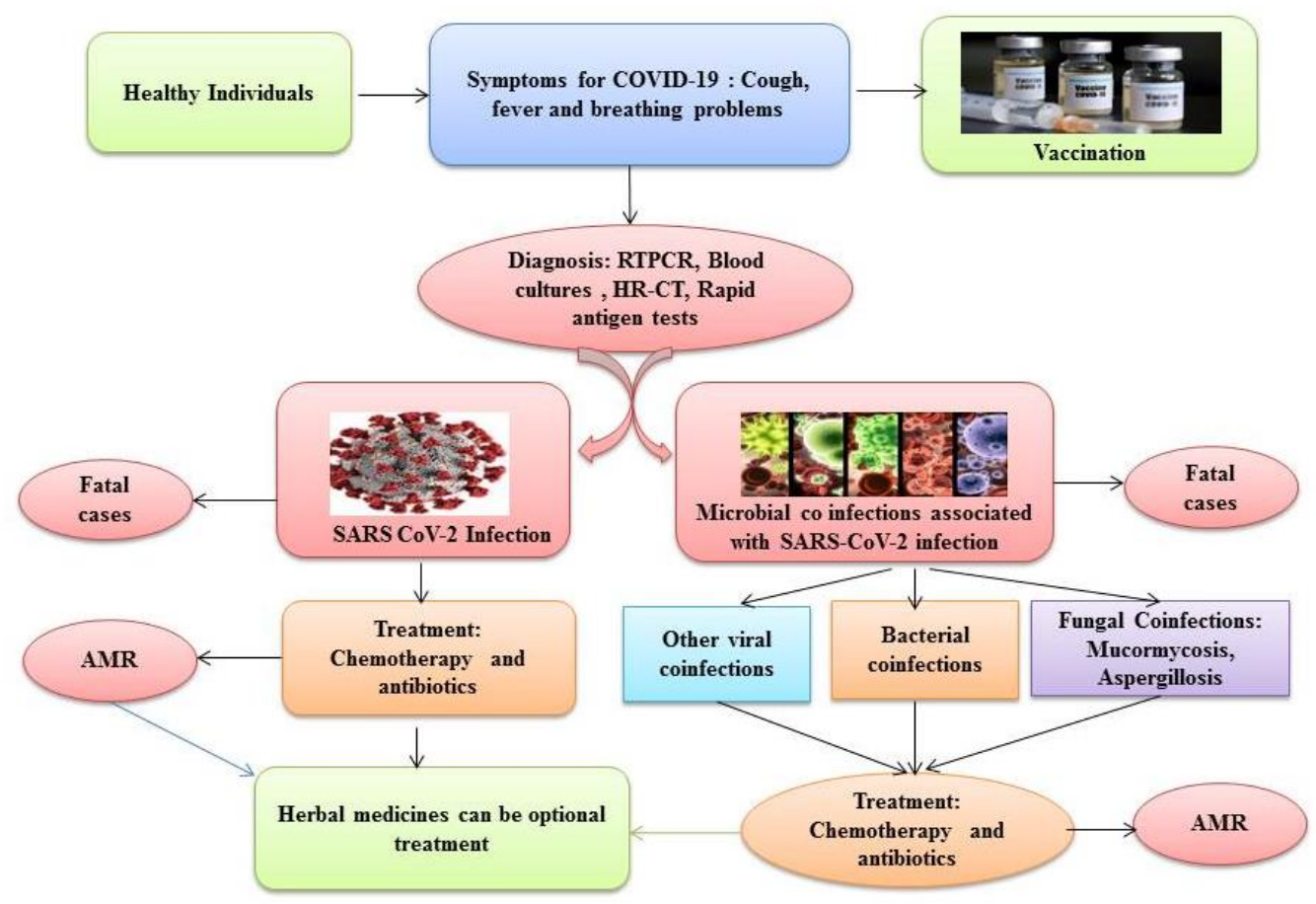

Fig. 2. Schematic representation of COVID-19 pandemic: Diagnosis, associated co-infections and treatment.

With stronger affinity to the ACE receptor, the variant B.1.1.7 [6], [7] shows mutations restricted to the NSP-6 domain of the spike protein gene N501Y, A570D, P681H, D614G, P681H, T716I, S982A, D1118H, H69/V70, Y144 deletion and S106/G107/F108 deletion in NSP-6 [8]. S106/G107/F108 deletion in NSP-6 is a common mutation in all the variants of SARS-CoV-2 that significantly affects the intracellular viral survival, pathogenicity, and the viral autophagy [9].

The South African variant 501.V2 has multiple mutations in the gene that encodes the spike protein that help the virus evade an antibody response [10]. The variant of Covid-19 first identified in India last October - called B.1.617.2 [11] is more transmissible than the UK/Kent variant - also known as B.1.1.7 - with no evidence that these variants cause much more serious illness. Very recently, a powerful COVID-2 variant $\mathrm{N} 440 \mathrm{~K}$ that spreads rapidly has been reported from southern parts of India. This variant is 15 times more virulent than the original variant and causes serious condition-stage within just three-four days as against symptoms of dyspnea or hypoxia within a week with the original variant. B.1.1.7 and B.1.617 are the 'UK Variant' and the Indian variant, also known as the 'double mutant.' Other variants B.1.525; B.1.427, B.1.616, B.1.1.28.1, B.1.1.28.2, B.1.1.28.3 [12][18]. The data is presented in Table I.

\begin{tabular}{|c|c|c|c|}
\hline $\begin{array}{l}\text { PANGO } \\
\text { Lineage }\end{array}$ & $\begin{array}{l}\text { Variant name/ } \\
\text { First reported }\end{array}$ & Key Mutations & References \\
\hline B.1.1.7 & $\begin{array}{l}\text { VOC } 202012 / 01 \text { or } \\
\text { Alpha/ UK }\end{array}$ & $\begin{array}{l}\text { N501Y, A570D, P681H, D614G, P681H, T716I, } \\
\text { S982A, D1118H, H69/V70, deletion Y144 } \\
\text { deletion and S106/G107/F108 deletion in NSP-6 }\end{array}$ & [6] and [7] \\
\hline $\begin{array}{l}\text { B.1.1.28.1 } \\
\text { (P.1) }\end{array}$ & $\begin{array}{l}\text { VOC 202101/02/ } \\
\text { Brazil \&Japan }\end{array}$ & $\begin{array}{l}\text { K417T; E484K; N501Y } \\
\text { deletion in NSP-6 }\end{array}$ & [15] \\
\hline $\begin{array}{l}\text { B.1.1.28.2 } \\
\quad(\mathrm{P} .2)^{*}\end{array}$ & $\begin{array}{l}\text { Gamma/ } \\
\text { Brazil } \\
\text { \& India }\end{array}$ & $\begin{array}{l}\text { L18F; T20N; P26S; F157L; E484K; D614G; } \\
\text { S929I; and V1176F } \\
\text { Indian Variant: E484K, N501Y and K417N }\end{array}$ & [16] and [17] \\
\hline $\begin{array}{l}\text { B.1.1.28.3 } \\
(\text { P.3)* }\end{array}$ & $\begin{array}{c}\text { PHL-B.1.1.28/ } \\
\text { Philippines \& Japan }\end{array}$ & 141-143 deletion E484K; N501Y; and P681H & [18] \\
\hline B.1.351 & $\begin{array}{l}\text { VOC 202012/02 } \\
\text { Or Beta/ South Africa }\end{array}$ & $\begin{array}{l}\text { L242/A243/L244 deletion; K417N; E484K; P71L } \\
\text { N; N501Y; D614G K417T;N501Y; T205IS; } \\
\text { A701V S106/G107/F108 and S106/G107/F108 } \\
\text { deletion in NSP-6 }\end{array}$ & $\begin{array}{c}{[6]} \\
{[10]}\end{array}$ \\
\hline B.1.427/B.1.429 & CAL.20C/L452R/USA & L452R; W152C; S13I; and D614G & [13] \\
\hline B.1.525* & UK \& Nigeria & $\begin{array}{l}\text { H69-V70 deletion; Y144 deletion; Q52R; E484K; } \\
\text { Q677H; D614G; and F888L }\end{array}$ & [14] \\
\hline B.1.616* & France & $\begin{array}{l}\text { G142 deletion; D66H; Y144V; D215G; V483A; } \\
\text { D614G; H655Y; G669S; Q949R; and N1187D }\end{array}$ & [12] \\
\hline B.1.617.1 & Kappa/ India & $484 \mathrm{Q}$ & [11] \\
\hline B.1.617.2 & Delta/India & $452 \mathrm{R}$ and $478 \mathrm{~K}$ & [11] \\
\hline
\end{tabular}




\section{BACTERIAL CO-INFECTIONS IN COVID-19 PATIENTS}

The patients infected with SARS-CoV-2 are more susceptible to microbial coinfections due to damage to the immune system, destruction of airway epithelium, reduced mucociliary clearance, and virus induced airway damage [19]-[21]. The bacterial respiratory infections are predominant among COVID-19 patients [22]. The secondary bacterial infection affects approximately $14.3 \%$ of COVID 19 patients [23].

Several bacterial co-infections reported in COVID-19 patients includes organisms. The data presented in Table II and III details the organisms detected in such cases.

Acinetobacter baumannii, Staphylococcus, Pseudomonas aeruginosa, Haemophilus influenzae, Serratia marscecens, Kliebsella pneumoniae, Corynebacterium spp., Streptococcus pneumoniae, Bacillus Spp., Micrococcus Spp., Proteus Spp., Enterobacter Spp., Citrobacter Spp., Escherichia coli, Enterobacter cloacae, Streptococcus pyogenes and Neisseria meningitidis. But the commonly found secondary infections include a specific group of bacterial pathogens, such as Haemophilus influenzae, Staphylococcus aureus, Streptococcus pneumoniae, Streptococcus pyogenes and Acinetobacter baumannii.

TABLE II: BACTERIAL COINFECTIONS ASSOCIATED WITH COVID-19 DISEASE

\begin{tabular}{|c|c|c|}
\hline $\begin{array}{l}\text { Bacterial coinfections in } \\
\text { COVID-19 } \\
\end{array}$ & Clinical manifestation/ Diagnostic Tests & References \\
\hline Haemophilus influenzae & $\begin{array}{l}\text { Pneumonia, acute bronchitis and Meningitis/ Blood } \\
\text { and spinal fluid cultures }\end{array}$ & [24] and [25] \\
\hline Staphylococcus aureus & $\begin{array}{l}\text { Staphylococcal pneumonia, Necrotizing pneumonia/ } \\
\text { Nasal secretions and blood culture echocardiogram, } \\
\text { RTPCR }\end{array}$ & [26], [27], [28] \\
\hline Streptococcus pneumoniae & $\begin{array}{l}\text { Sepsis, meningitis, otitis media Pneumococcal } \\
\text { pneumonia/Urinary antigen test, chest } \mathrm{x} \text {-ray }\end{array}$ & [29] \\
\hline Streptococcus pyogenes & $\begin{array}{l}\text { Sepsis, pleural empyema, mild skin and soft tissue } \\
\text { infections, pharyngitis, tonsillitis/Lancefield group A } \\
\text { antigen test }\end{array}$ & [35] \\
\hline Kliebsella pneumoniae & $\begin{array}{l}\text { Pneumonia/sputum, urine, or blood culture, X-ray and } \\
\text { High resolution computerized tomography (HR-CT) }\end{array}$ & {$[20]$} \\
\hline Acinetobacter baumannii & $\begin{array}{l}\text { Pneumonia/Sputum, blood, and cerebrospinal fluid } \\
\text { culture }\end{array}$ & [74] \\
\hline Mycoplasma pneumoniae & Interstitial pneumonia/ IgA-based serological assay & [20] \\
\hline Pseudomonas aeruginosa & $\begin{array}{l}\text { sputum, urine, or blood culture and crossed immune } \\
\text { electrophoresis (CIE) }\end{array}$ & {$[51]$} \\
\hline Legionella pneumophila & $\begin{array}{l}\text { Pneumonia and Legionnaire's disease/ Urinary antigen } \\
\text { test }\end{array}$ & {$[20]$} \\
\hline Enterobacter cloacae & Pneumonia/Blood culture & [20] \\
\hline
\end{tabular}

TABLE III: COMMON RESPIRATORY VIRAL-BACTERIAL CO-INFECTIONS AND THEIR ASSOCIATED CLINICAL INFECTIONS IN HUMAN

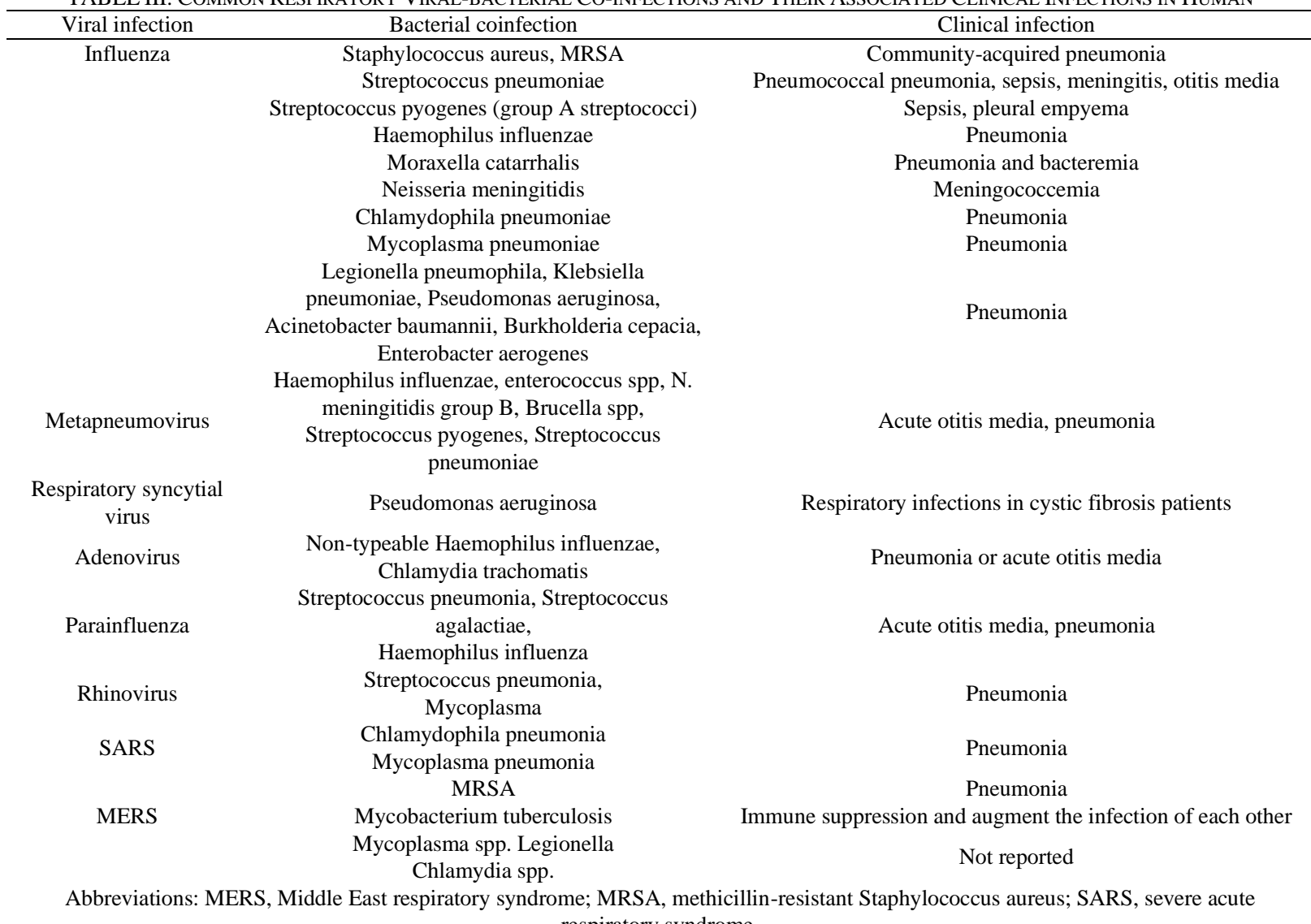
respiratory syndrome. 


\section{A. Haemophilus Influenzae}

It is a facultative anaerobic, gram negative, coccobacillus mainly associated with community acquired pneumonia (CAP) and the most common bacterial coinfection found in COVID-19 patients [24]. It colonizes the upper respiratory tract; capsular polysaccharide produced during pathogenesis is a critical virulence factor that helps during invasion of bloodstream and hematogenous dissemination [25]. According to a study by Calcagno et al. [22], the film array data showed the presence of $H$. influenzae in 15 patients out of 63 patients hospitalized for respiratory infections and the two patients from the same group were found positive for SARS-CoV-2 infection.

\section{B. Staphylococcus aureus}

Staphylococcus aureus is a Gram-positive cocci that causes a multitude range of diseases in humans and increases the complications of viral infections. Staphylococcal pneumonia can be usually seen after viral infections and it is one of the leading causative agents of ventilator-associated pneumonia. In a recent retrospective study by Cusumano et al. [26], found that $54.8 \%$ patients hospitalized for COVID19 with $S$. aureus bacteremia died in 14 days from the first positive blood culture. Coinfections of $S$. aureus acts synergistically to cause pneumonia and trigger the fatality rate in patients. In a case report by Duployez et al. [27], a superinfection of Panton-Valentine leucocidin-secreting $S$. aureus causing necrotizing pneumonia is reported and the patient died after 14 days. They have proposed that SARSCoV-2 infection is also a facilitating factor for PVLproducing $S$. aureus necrotizing pneumonia [28].

\section{Streptococcus pneumoniae}

Streptococcus pneumoniae is a coccoid, gram positive hematolytic facultative anaerobic bacterium responsible for pneumococcal pneumonia due to colonization of nasopharynx and it is also responsible for sepsis and meningitis [29]. Due to unavailability of specific and rapid screening test for the diagnosis of pneumococcal pneumonia, lack of laboratory and radiological specific findings; there is possibility of overlooking $S$. pneumoniae coinfection in COVID-19 patients.

Anton-Vazquez and Cliville, [30] reported that $87(8 \%)$ patients out of 2782 patients tested positive for SARS-CoV2 were coinfected with $S$. pneumoniae and the coinfection was prevalent in females. Nearly $57 \%$ (p < 0.001) of female patients co-infected with COVID-19 suffered pneumococcal pneumonia in comparison with patients with COVID-19 infections without pneumococcal pneumonia. They have proposed that further investigation is needed to understand the risk of coinfection and susceptibility of female patients to coinfection. The vaccination for pneumonia in COVID-19 patients is recommended to decrease the severity of the disease and to increase the coverage rates.

In another study by Rodriguez-Nava et al. [31], urine antigen test was used to diagnose the $S$. pneumoniae coinfections in COVID-19 patients. They have reported 11 cases of coinfections during March 1, 2020, and June 30, 2020 at AMITA Health Saint Francis Hospital, Evanston, USA. 7 patients died while 4 patients were discharged in stable conditions and the reported mortality rate was $64 \%$ of coinfected patients. In a case series study, Cucchiari et al. [32] reported the superinfection S. pneumoniae in 5 patients admitted for COVID-19 disease. The chest $\mathrm{x}$-ray of the patients revealed that there were bilateral interstitial infiltrates in 3 cases, bilateral consolidative infiltrates, and unilateral consolidative infiltrate in one case each. The indistinguishable radiological pattern of COVID-19 patients from pneumococcus pneumonia can delay the diagnosis of SARS-CoV-2 association with pneumococcal pneumonia.

\section{Streptococcus pyogenes}

Streptococcus pyogenes is a Gram positive coccoid aero tolerant bacterium which belongs to Group A streptococci [33] and causes wide range of infections in humans ranging from self-recovering localized infection to severe lifethreatening invasive infections [34]. Khaddour et al. [35] 2020 reported a case of 56 year old female who was tested positive for A Streptococcus antigen test. The X-ray of chest revealed the worsening bilateral diffuse opacities and within a day the female patient was tested positive for SRAS-CoV2. The patient was discharged after 3 weeks of treatment with hydroxychloroquine sulfate and tocilizumab and shifted to inpatient rehabilitation.

\section{E. Acinetobacter baumannii}

Acinetobacter baumannii is a Gram negative, aerobic, pleomorphic bacterium mainly responsible for nosocomial infections including urinary tract infections, bacteremia, meningitis, and lung infections. Serum resistance due to outer membrane protein A (OmpA) and acceleration of local innate immunity response due to production of different virulence related proteins are the two important virulence factors involved in pathogenesis [36].

Durán-Manuel et al. [37] reported a clonal distribution of A. baumannii (AdeABCRS ${ }^{+}$) among the patients hospitalized for SARS-CoV-2 infection at Hospital Juarez de, Mexico. It was found that percentage of A. baumannii among gram negative bacteria isolated from COVID-19 patients was approximately 52\%. In another study, Sharifipour et al. [38], found that, out of 19 patients admitted for COVID-19 disease at ICU wards in two referral hospitals in Qom, Iran, $90 \%$ patients were positive for A. baumannii that were all antibiotic resistant and $10 \%$ found positive for S. aureus and emphasizing the chances of superinfection. Interestingly, the $S$. aureus was methicillin resistant while the other was sensitive to methicillin. The samples were collected from the respiratory tract of all the patients, who succumbed to the covid infection except the patient who showed presence of antibiotic sensitive $S$. aureus.

\section{BENEFITS OF BACTERIA IN COVID PATIENTS}

Studies have shown that bacterial sphingomyelinase (bSMase) suppresses replication of influenza virus and severe acute respiratory syndrome coronavirus 2 (SARS-CoV-2), but not the replication of rhinovirus [39]. bSMase inhibited the replication of both IBV and SARS-CoV-2 at a concentration as low as 0.1 units $\mathrm{ml}-1$ and shown to reduce the replication of hepatitis C virus (HCV) [40], Ebola virus [41], Rubella virus [42], and Pseudorabies virus [43]. In the study by Shen et al. [44], the level of serum sphingolipids is 
reduced in both severe and non-severe COVID-19 patients.

Sphingomyelin is the dominant sphingolipid in the membranes of mammalian cells, and are important for several cellular processes, including the regulation of endocytosis, ion channel and organization of proteins within membranes. Acid sphingomyelinase, a lysosomal enzyme that converts sphingomyelin into ceramide, plays in cellular infection with SARS-CoV-2 [45], where it helps the viral entry and then its replication.

\section{Fungal Co-INFECTIONS IN COVID-19 PATIENTS}

The chances of fungal coinfections such as candidaemia, pulmonary aspergillosis and tracheobronchitis are increased due to severe clinical situations during COVID-19 pandemic [46]. The fungal infections associated with COVID-19 patients may be missed due to misdiagnosis and limitations of diagnostic methods available. Thus, very few articles are available reporting fungal coinfections associated with SARS-CoV-2 [47]. Severely affected patients admitted to ICU are more prone to develop fungal infections due to prolonged use of ventilator and longer duration of treatment at the hospital [48].

In a retrospective cohort study, Garcia-Vidal et al. [49] have found that $0.7 \%$ patients among 989 patients admitted for SARS-CoV-2 infection have developed hospital acquired fungal coinfections and total three fatal cases reported at Hospital Clinic of Barcelona (Spain) among fungal coinfected patients. Three patients suffering from tracheobronchitis was caused by Aspergillus fumigatus and two patients had developed bacterial and fungal superinfection. Among four patients coinfected with Candida albicans, two patients were diagnosed with candidaemia and one case of nosocomial urinary tract infection due to contaminated urinary catheter reported.

In another retrospective study at Jinyintan Hospital in Wuhan, China, it was reported that $5 \%$ patients among 99 patients admitted for COVID-19 disease were associated with fungal coinfection including three patients tested positive for Candida albicans, a case of Aspergillus flavus coinfection and Candida glabrata infection associated with one patient [50]. Hence, the frequency of coinfection and its severity varies in different parts of the world and found discretion of Health Policies of each country and also the diagnostic and hygienic facilities available at the hospital.

\section{A. Pulmonary Aspergillosis in COVID-19 Patients}

Pulmonary aspergillosis is a clinical term used for the spectrum of diseases caused by infection with a fungus Aspergillus spp. Different species such as A. fumigatus, A. terrus, and A. flavus are involved in pathogenesis of pulmonary aspergillosis but $A$. fumigatus is the most common etiological agent. The pulmonary aspergillosis usually found in patients with immunodeficiency, is also reported in COVID-19 patients especially in critical illness [51]. As SARS-CoV-2 infection damages the airway epithelium, enabling aspergillus invasion and further clinical manifestations results in the development of aspergillosis [52]. During the ongoing COVID-19 pandemic, several cases of pulmonary aspergillosis associated with SARS-CoV-2 infection were reported from different parts of the world [53]-
[55].

In a cases series study by Benedetti et al. [56] at Posadas Hospital, Buenos Aires, Argentina, five presumptive cases of invasive pulmonary aspergillosis associated with COVID-19 patients are reported. All the 5 patients were admitted in ICU, one was immunocompromised and four were immunocompetent patients and having history of insulin dependent diabetes, diabetes type 2, arterial hypertension, obesity, B cell acute lymphoblastic leukemia and bronchiectasis. Three patients were tested positive for sputum culture for A. fumigatus. Intravenous injection of lipid-based formulations of amphotericin B and Voriconazole were used to control the fungal invasion but unable to recover the patients completely and one patient died due to respiratory and hemodynamic instability and sepsis.

\section{B. Mucormycosis in COVID-19 Patients}

Mucormycosis is a fungal angioinvasive disease caused due to inhalation of fungal spores. The fungi of genus viz Rhizopus, Cunninghamella and Absidia are involved in pathogenesis of mucormycosis but Rhizopus oryzaelarrhizus is the most common causative agent worldwide [57]. The disease is commonly associated with immunocompromised patients and it is more lethal as compared to other fungal infections with $40-50 \%$ survival rate [58]. Patients with diabetes mellitus, tuberculosis infection and chronic renal failure are the major risk groups for mucormycosis infection. Several cases of mucormycosis associated with COVID-19 patients were reported especially from India during this ongoing COVID-19 pandemic [59]-[61] and it was proposed that COVID- 19 patients are more susceptible to mucormycosis infection [62]. India has reported 14000 positive cases of mucormycosis during the second wave of COVID-19 pandemic and contributed $71 \%$ of positive cases globally: the two states of India namely Maharashtra and Gujarat accounts for more than $30 \%$ of positive cases [63]. The mucormycosis is predominantly seen in males (78.9\%) among the patients with SARS-CoV-2 infection and patients recovered from COVID-19 [64].

In a case report by Mehta and Pandey [59], a 60 year old diabetic patient was admitted at Lilavati Hospital, Mumbai, India for three-day history of severe breathlessness, pyrexia, tachypnea, and generalized malaise. The RT-PCR test of the patient was positive for SARS-CoV-2 infection. The patient had developed orbital cellulitis and magnetic resonance imaging of patient revealed that swelling of soft tissue right preseptal, malar, premaxillary and retrobulbar regions with paranasal sinusitis. In the nasal biopsy, the presence of aseptate filamentous fugal hyphae confirmed the confirmed the association of mucormycosis. The patient was on noninvasive ventilation and treated with intravenous meropenem and vancomycin with amphotericin-B after the completion of steroid therapy but despite of all the measures attempted, the patient died on $6^{\text {th }}$ day after hospitalization. They concluded that widespread use of broad spectrum antibiotics, monoclonal antibodies and steroids for the treatment of COVID-19; increase the chance of secondary fungal and bacterial infections due to deterioration or dysregulation of immune system. Thus, early diagnosis is a necessary control measure for scaling down the mortality rate in patients with preexisting risk factors. 
In a series of case studies, Sarkar et al. [65] reported 10 positive cases of mucormycosis associated with SARS-CoV2 infection with the 2-month span from October 2020 to November 2020. All the patients reported positive for mucormycosis were with diabetic history; 4 patients were associated with Diabetic ketoacidosis (DKA) and 5 patients had developed KDA after the initiation of corticosteroid therapy for COVID-19 disease. All the patients were on the treatment of intravenous dexamethasone while four patients were received the remdesivir for the COVID-19 treatment. The liposomal amphotericin B was used for the treatment of mucormycosis but still four lethal cases were reported during this cases series. Five patients were recovered from systemic infection but with irreversible vision loss while a single patient was discharged due to improved health condition suggesting the high mortality rate among COVID-19 patients associated angioinvasive fungal infection.

Currently, lipid-based formulations of amphotericin B is a standard treatment available for mucormycosis. In addition, posaconazole was also used for salvage therapy but not recommended for primary treatment [66] while Polymyxin E was also used [67] in few cases. But the excessive use of amphotericin B $(0.5 \mathrm{mg} / \mathrm{kg} /$ day $)$ and related steroids affects adversely which leads to development of DKA and creates further complications [59], [65]. Vediyappan et al. [68] reported that gymnemic acid, an active constituent of Gymnema sylvestre leaves extract can inhibit the growth of fungal hyaphe of Candida albicans and Aspergillus spp. Surapuram et al. [69] reported several plant extracts such as Ardisia solomonii, Agathis atropurpurea, Amphitechna haberi, Conradina canescens, Drymonia conchocalyx, Camellia sinensis, Mauria heterophylla and Turpinia occidentalis exhibits potent antifungal activity against Rhizopus stolonifer and Aspergillus niger. Thus, such herbal preparations can be good options for the treatment of mucormycosis.

\section{VIRAL CO-INFECTIONS IN COVID-19 PATIENTS}

Respiratory viral coinfections such as Coronavirus HKU1, Enterovirus/rhinovirus, $\quad \mathrm{H}_{1} \mathrm{~N}_{1}, \quad \mathrm{H}_{3} \mathrm{~N}_{2}, \quad$ Human metapneumovirus (hMPV), Influenza A, Metapneumovirus, Parainfluenza and Respiratory syncytial virus (RSV) are commonly associated with SARS-CoV-2 infection [70].

In a study by Ma et al. [71] at Wuhan Union Hospital in China between Jan 19, 2020, and Feb 26, 2020, several positive cases of viral coinfection with SARS-CoV-2 is reported. The RT-PCR test was used for detection of Influenza A, influenza B and RSV while chemiluminescence immunoassay was used for detection adenovirus. Among 250 positive cases of COVID-19, RSV was found in 12 patients $(4.8 \%)$, Adenovirus in 7 patients $(2.8 \%)$, influenza $\mathrm{A}$ in 2 patients $(0.8 \%)$ and Influenza B in 1 patient $(0.4 \%)$.

During early outbreak of COVID-19, Burrel et al. [72] reported 280 positive cases of COVID-19 at Pitie-Salpetriere hospital, Paris. A total of 1423 patients were admitted for respiratory tract infections; out of them 724 (50.9\%) patients tested negative for viral infections while 398 (28\%) patients were positive for other respiratory viral infections and 21 $(1.5 \%)$ patients were with viral coinfections associated with SARS-CoV-2. The viral coinfections include 6 cases of non-
SARS-CoV-2 coronavirus, five cases of influenza virus, 3 cases of adenovirus, 3 patients found positive for rhinovirus/enterovirus, 3 cases of parainfluenza virus, and single patient infected with adenovirus + rhinovirus/enterovirus.

\section{ESKAPE PATHOGENS AND COVID-19 PANDEMIC}

As prolonged treatment is required for critically ill patients hospitalized for SARS-CoV-2 infections; the contamination of surgical equipment's, ventilators and medical devices increases the chances of coinfections of multidrug resistant ESKAPE pathogens in COVID-19 patients. Several articles were reported coinfection of ESKAPE pathogens in COVID19 patients such as Acinetobacter baumannii [73], Enterococcus faecium [74], Escherichia coli [75], Kliebsella pneumoniae) [76], Pseudomonas aeruginosa [77] and Staphylococcus aureus [78]. Anti-microbial resistance (AMR) is a very common among ESKAPE pathogens. Thus, co-infections with ESKAPE pathogen can create hurdles in effective treatment of COVID-19 patient and increase the health risk.

Studies by Mahmoudi [79] have shown that the secondary bacterial infections were associated with COVID 19 patients. In a cross sectional study of 340 patients using blood culture and endotracheal aspirate, total of 43 patients $(12.46 \%)$ were found positive for ESKAPE pathogens including 11 positive cases of Klebsiella species, 9 cases of methicillin-sensitive Staphylococcus aureus (MSSA), 6 cases of methicillinresistant Staphylococcus aureus (MRSA), 7 cases of Escherichia coli coinfection, 5 of Enterobacter species, 4 cases of Pseudomonas aeruginosa and a single case of Streptococcus pneumoniae coinfection. Durán-Manuel et al. [37] isolated ESKAPE pathogens from Sixty-one sites out of 67 sites used for the study (medical devices, inert surfaces, medical personnel, and patients) from the intensive care unit of the Hospital Juarez de Mexico, a dedicated hospital for COVID-19 patients. Gram positive bacteria were isolated from $24(39.3 \%)$ sites while Gram negative bacteria were isolated from 37 sites (60.6\%) and 10 sites (6.1\%) were contaminated with both Gram positive and Gram negative bacteria. Among isolated ESKAPE pathogens, A. baumannii and $S$. aureus were predominantly found in 13 and 11 sites respectively.

\section{ANTIMICROBIAL RESISTANCE (AMR) STATUS OF BACTERIA FOUND IN COVID-19 PATIENTS}

Antimicrobial resistance (AMR) is major global health concern emerged in last few decades due to excessive and unregulated use of antibiotics and antimicrobial drugs. Excessive use of antimicrobials drives the increase in frequency of AMR phenotypes of infectious pathogens and also creates a selective pressure for the evolution of AMR phenotypes [80]. Global connectivity of human population allows environmental access to enter such phenotypes worldwide. AMR adversely affects the effective prevention of several infectious diseases caused by bacteria, fungi, parasites and viruses. It has been estimated that by 2050 , AMR will be responsible for 10 million deaths worldwide, 
$2 \%$ to $3.5 \%$ of reduction in Gross Domestic Product (GDP) and it will adversely affect the economy by costing approximately US\$ 100 trillion [81].

As several bacterial, fungal, and viral coinfections are associated with COVID-19 patients, there is a necessity to review the AMR status of such pathogens. It has been reported that although the coinfection rate in patients hospitalized for COVID-19 infection varies from 1-15\%, there is tendency in increased use of antibiotic and antimicrobial drugs [82]. Thus, an appropriate antibiotic or antimicrobial agent must be selected against such coinfections with optimal dose and duration for the effective treatment. Otherwise, excessive, and prolonged use of ineffective antibiotics would result in an outbreak of resistant phenotypes during this critical clinical situation of COVID19 pandemic.

One such outbreak of Carbapenem resistant Acinetobacter baumannii (CRAB) was reported by Perez et al. [83] in New Jersey Hospital (Hospital A) on May 28, 2020. During FebJuly 2020, 34 patients were found positive for blood culture of CRAB that includes $17(50 \%)$ patients with infection of SARS-CoV-2. The 28 cases of CRAB infection reported during facility surge in SARS-CoV-2 infections. Among 34 patients with CRAB infections, 10 (29\%) patients were associated with ventilator associated pneumonia, 4 cases $(12 \%)$ with ventilator associated pneumonia with bacteremia, $3(9 \%)$ patients with bacteremia, $3(9 \%)$ patients with bone and soft tissue infection and $14(41 \%)$ patients were found with CRAB colonization.

Randall and Minahan, [84] reported 3 cases of COVID-19 patients with Methicillin resistant $S$. aureus (MRSA) infection in country hospital of Riverside University Health system. A 60 year old male patient was hospitalized for fever cough and dyspnea in April 2020 and was tested negative for MRSA. Within 3 days after hospitalization the patient was tested positive for MRSA and died on the same day due to respiratory distress. Likewise, another two patients were admitted in May 2020 and June 2020 was tested positive for MRSA after hospitalization. One patient died after 14 days due to septic shock while other died due to staphylococcal pneumonia after 10 days of hospitalization. As no patient was admitted for MRSA infection within the duration of April 2020 to June 2020; still 3 patients were tested positive for MRSA, it suggests that patients have acquired nosocomial infections of MRSA after hospitalization or COVID-19 infection make the patients more susceptible to MRSA infection. The studies on antibiotic susceptibility of bacterial isolates from COVID-19 patients have shown that the members of Enterobacteriaceae family were highly resistant to common antibiotics such as cotrimoxazole (74\%), piperacillin $(67.5 \%)$, ceftazidime $(47.5 \%)$, and cefepime (42.5\%). The $S$. aureus species isolated were resistant to erythromycin and clindamycin but found susceptible to vancomycin $(100 \%)$ while the isolated P. aeruginosa found to be susceptible to imipenem [79].

Gottesaman et al. [85] 2021 reported another outbreak of CRAB in a COVID-19 dedicated Hasharon Hospital, Israel. Of affected patients, five patients were tested positive for blood culture for CRAB with 2 fatal cases. In this hospital also, no patient was hospitalized for CRAB infection prior to opening of the hospital on 27 March 2021, implying that all the patients acquired nosocomial infection of CRAB in the hospital. Environmental sampling of ward-D and ICU reveled that out of 63 samples of ward-D, 7 samples tested positive for CRAB while all the 60 samples from ICU were negative. All the isolates of A. baumannii belonged to international clonal lineage 2 (blaoxA-66 allele) and harbored the blaoxA-24-like carbapenemase.

\section{HAND SANITIZERS AND DISINFECTANT INDUCED AMR}

During COVID-19 pandemic there is a notable surge in the use of disinfectants, alcohol-based hand sanitizers and antimicrobial agents. Excessive use of sanitizers to prevent further transmission of SARS-CoV-2 infection and to inhibit or kill the virus can induce the emergence of AMR phenotypes. Animal viruses cannot survive under environmental conditions without host for a longer period of time, but bacteria can survive and reproduce [86] and thus there are chances of inheritance of AMR phenotypes over generations. The exact mechanism for the transfer of disinfectant resistance phenotypes is unknown. Horizontal gene transfer and conjugation of plasmids encoding for disinfectant resistance genes are the two possible mechanisms for acquisition of disinfectant resistance phenotypes [87].

Pittet et al. [88] reported that the newer strains of Enterococcus faecium are more tolerant to alcohol-based sanitizers. The study showed that vancomycin resistant enterococci (VRE) strains spread more quickly as compared to other strains. Hence, alcohol-based sanitizers are not recommended for VRE environmental control. Thus, hand sanitizers and disinfectants must be used appropriately at optimal concentration to avoid the survival of resistant microbial strains. Proper disposal of used disinfectants, hand sanitizers and bactericidal agents is necessary to avoid the environmental contamination. Mitsuboshi and Tsugita, [89] reported that appropriate hand hygiene using alcohol based sanitizers decreased the isolation rates MRSA and multidrugresistant Pseudomonas aeruginosa (MDRP) by preventing the further dissemination of antibiotic resistance bacteria among patients hospitalized in small to medium-sized Japanese hospitals.

\section{A. Herbal Biomolecules}

Several herbal biomolecules have antiviral activity against SARS related viruses such as glycyrrhizin from Glycyrrhiza glabra, Myricetin from Myrica rubra, Scutellarein from Scutettaria baicalensis, quercetin, luteolin, apigenin and lycorine from Torreya nucifera and lycorine from Lycoris radiata [90]. As single antiviral drugs are not enough to completely cure the COVID-19 and related manifestations caused by associated coinfections; thus, there is need to investigate the synergistic combinations of available drugs with herbal antiviral biomolecules.

\section{Conclusions}

ESKAPE pathogens are predominant among the nosocomial infections associated with COVID-19, thus care should be taken to sanitize the hospitals, ventilators and other equipment's on regular basis with optimal concentration of disinfectants. Avascular necrosis or bone death sets in due to 
intake of steroids in Covid patients and also such patients developing blood clots. Avascular necrosis predisposes joints to a septic process particularly in the immunosuppressed individual [91], hence involvement of bacteria in such clinical conditions appears relevant.

\section{CONTRIBUTORSHIP}

Rajkumar contributed to collection of literature, assimilating the available information and classified the technical information into sections and made tables and figures as required. Rajkumar also prepared the preliminary draft of this review paper.

Sasidharan Sakkan assimilated the available data on microbial infections seen in covid patients and contributed to making necessary tables for this review paper.

Sriram Padmanabhan arrived at the concept of drafting a mini review on information of all kinds of microorganisms seen in covid patients and prepared the final manuscript with reformatting the entire paper and the references as required by the journal.

\section{ACKNOWLEDGMENTS}

The authors are thankful to the Chairman, Vinod Ramachandra Jadhav, SAVA Healthcare Limited for his constant support and encouragement.

\section{REFERENCES}

[1] Nalbandian A., Sehgal K., Gupta A., Madhavan M., McGroder C., Stevens J., et al. Post-acute COVID-19 syndrome. Nat Med. 2021; 27(4):601-615. doi: 10.1038/s41591-021-01283-Z.

[2] Tang X., Wu C., Li X., Song Y., Yao X., Wu X. On the origin and continuing evolution of SARS-CoV-2. Natl Sci Rev. 2020; nwaa036. doi: 10.1093/nsr/nwaa036.

[3] Raj C., Kandaswamy D., Danduga R., Rajasabapathy R., James R., et al. COVID-19: molecular pathophysiology, genetic evolution and prospective therapeutics-a review. Arch Microbiol. 2021; 203(5):20432057 doi: 10.1007/s00203-021-02183-z.

[4] Sogaard K., Baettig V., Osthoff M., Marsch S., Leuzinger K., Schweitzer M., et al. Community-acquired and hospital-acquired respiratory tract infection and bloodstream infection in patients hospitalized with COVID-19 pneumonia. J Intensive Care. 2021;18; 9 (1):10.doi: 10.1186/s40560-021-00526-y

[5] Yadav P., Nyayanit D., Sahay R., Sarkale P., Pethani J., Patil S., et al. Isolation and characterization of the new SARS-CoV-2 variant in travellers from the United Kingdom to India: VUI-202012/01 of the B.1.1.7 lineage. J Travel Med. 2021; 28 (2):taab009. doi: 10.1093/jtm/taab009.

[6] Galloway S., Paul P., MacCannell D., Johansson M., Brooks J., MacNeil A., et al. Emergence of SARS-CoV-2 B.1.1.7 Lineage United States, December 29, 2020-January 12, 2021. MMWR Morb Mortal Wkly Rep. 2021; 70(3):95-99. doi: 10.15585/mmwr.mm7003e2.

[7] Davies N., Abbott S., Barnard R., Jarvis C., Kucharski A., Munday J., et al. COVID-19 Working Group; COVID-19 Genomics UK (COGUK) Consortium, Diaz-Ordaz K., Keogh R., Eggo R.M., Funk S., Jit M., Atkins K., Edmunds W. Estimated transmissibility and impact of SARS-CoV-2 lineage B.1.1.7 in England. Science 2021; 372(6538): eabg3055. doi: 10.1126/science.abg3055

[8] Sallam M., Mahafzah A. Molecular Analysis of SARS-CoV-2 Genetic Lineages in Jordan: Tracking the Introduction and Spread of COVID19 UK Variant of Concern at a Country Level. Pathogens. 2021; 10(3):302. doi: 10.3390/pathogens 10030302.

[9] Benvenuto D., Angeletti S., Giovanetti M., Bianchi M., Pascarella S., Cauda R., et al. Evolutionary analysis of SARS-CoV-2: how mutation of Non-Structural Protein 6 (NSP6) could affect viral autophagy. $J$ Infect. 2020; 81(1):e24-e27. doi: 10.1016/j.jinf.2020.03.058.

[10] Wibmer C.K., Ayres F., Hermanus T, Madzivhandila M., Kgagudi P., Oosthuysen B., et al. SARS-CoV-2 501Y.V2 escapes neutralization by
South African COVID-1 McCallum 9 donor plasma. Nat Med, 2021; 27: 622-25. https://doi.org/10.1038/s41591-021-01285-x.

[11] Adam D. The rush to study fast spreading coronavirus variants. Nature. 2021; 594 19-20. doi: 10.1038/d41586-021-01390-4.

[12] Fillatre P., Dufour M.-J., Behillil S., Vatan R., Reusse P., Gabellec A., et al. A new SARS-CoV-2 variant poorly detected by RT-PCR on nasopharyngeal samples, with high lethality. medRxiv 2021;05.05.21256690; doi: 10.1101/2021.05.05.21256690.

[13] McCallum M., Bassi J., Marco A.D., CHEN A., Walls A.C., Iulio J.D. Tortorici A., et al. SARS-CoV-2 immune evasion by variant B.1.427/B.1.429. bioRxiv. 2021; $437925 . \quad$ doi 10.1101/2021.03.31.437925

[14] Zhou W., Wang W. Fast-spreading SARS-CoV-2 variants: challenges to and new design strategies of COVID-19 vaccines. Sig Transduct Target Ther. 2021; 6, 226. https://doi.org/10.1038/s41392-021-00644$\mathrm{x}$.

[15] Francisco R. Jr, Benites L., Lamarca A., de Almeida L., Hansen A., Gularte J., et al. Pervasive transmission of E484K and emergence of VUI-NP13L with evidence of SARS-CoV-2 co-infection events by two different lineages in Rio Grande do Sul, Brazil. Virus Res. 2021; 296:198345. doi: 10.1016/j.virusres.2021.198345.

[16] Sapkal G., Yadav P., Ella R., Abraham P., Patil D., Gupta N., et al. Neutralization of B.1.1.28 P2 variant with sera of natural SARS-CoV2 infection and recipients of inactivated COVID-19 vaccine Covaxin. J Travel Med. 2021; taab077. doi: 10.1093/jtm/taab077.

[17] Yadav P., Mohandas S., Sarkale P., Nyayanit D., Shete A., Sahay R., et al. Isolation of SARS-CoV-2 B.1.1.28.2 P2 variant and pathogenicity comparison with D614G variant in hamster model. bioRxiv [Preprint] 2021. doi: 10.1101/2021.05.24.445424

[18] Tablizo F., Kim K.M., Lapid C.M., Castro M.J.R., Yangzon M.S.L., Maralit B.A., Ayes M.E.C., et al. Genome sequencing and analysis of an emergent SARS-CoV-2 variant characterized by multiple spike protein mutations detected from the Central Visayas Region of the Philippines. medRxiv 2021;03.03.21252812; doi: 10.1101/2021.03.03.21252812.

[19] Vareille M., Kieninger E., Edwards M., Regamey N. The airway epithelium: soldier in the fight against respiratory viruses. Clin Microbiol Rev. 2011; 24(1):210-29. doi: 10.1128/CMR.00014-10.

[20] Mirzaei R. Goodarzi P., Asadi M., Soltani A., Aljanabi H., Jeda A., et al. Bacterial co-infections with SARS-CoV-2. IUBMB Life. 2020; 72(10):2097-2111. doi: 10.1002/iub.2356

[21] Denney L, Ho L. The role of respiratory epithelium in host defence against influenza virus infection. Biomed J. 2018; 41(4):218-233. doi 10.1016/j.bj.2018.08.004.

[22] Calcagno A., Ghisetti V., Burdino E., Trunfio M., Allice T., Boglione L., et al. Co-infection with other respiratory pathogens in COVID-19 patients. Clin Microbiol Infect. 2021; 27(2):297-298. doi: 10.1016/j.cmi.2020.08.012.

[23] Sarkar S., Khanna P., Singh A. Impact of COVID-19 in patients with concurrent co-infections: A systematic review and meta-analyses. $J$ Med Virol. 2021a; 93(4):2385-2395. doi: 10.1002/jmv.26740.

[24] Lansbury L., Lim B., Baskaran V., Lim W. Co-infections in people with COVID-19: a systematic review and meta-analysis. J Infect. 2020; 81(2):266-275. doi: 10.1016/j.jinf.2020.05.046.

[25] Agrawal A., Murphy T. Haemophilus influenzae infections in the $\mathrm{H}$ influenzae type b conjugate vaccine era. J Clin Microbiol. 2011; 49(11):3728-3732. doi: 10.1128/JCM.05476-11.

[26] Cusumano J., Dupper A., Malik Y., Gavioli E., Banga J., Caban A.B., et al. Staphylococcus aureus bacteremia in patients infected with COVID-19: A case series. Open Forum Infect Dis. 2020; 7(11):ofaa518. doi: 10.1093/ofid/ofaa518.

[27] Duployez C., Le Guern R., Tinez C., Lejeune A.L., Robriquet L., Six S., et al. Panton-valentine leukocidin-secreting Staphylococcus aureus pneumonia complic Wibmer ating COVID-19. Emerg Infect Dis. 2020; 26(8):1939-1941. doi: 10.3201/eid2608.201413.

[28] Dudoignon E., Caméléna F., Deniau B., Habay A., Coutrot M., Ressaire Q., et al. Bacterial Pneumonia in COVID-19 Critically Ill Patients: A Case Series. Clin Infect Dis. 2021; 72(5):905-906. doi 10.1093/cid/ciaa762.

[29] Henriques-Normark B., Tuomanen E. The Pneumococcus: epidemiology, microbiology, and pathogenesis. Cold Spring Harb Perspect Med. 2013; 3(7):a010215. doi: 10.1101/cshperspect.a010215.

[30] Anton-Vazquez V., Clivillé R. Streptococcus pneumoniae co-infection in hospitalized patients with COVID-19. Eur J Clin Microbiol Infect Dis. 2021;19:1-3. doi: 10.1007/s10096-021-04166-w.

[31] Rodriguez-Nava G., Yanez-Bello M., Trelles-Garcia D., Chung C., Egoryan G., Friedman H.J. A retrospective study of co-infection of SARS-CoV-2 and Streptococcus pneumoniae in 11 hospitalized patients with severe covid-19 pneumonia at a single center. Med Sci Monit. 2020; 26:e928754. doi: 10.12659/MSM.928754. 
[32] Cucchiari D., Pericàs J., Riera J., Gumucio R., Md E., Nicolás D. Pneumococcal superinfection in COVID-19 patients: A series of 5 cases. Med Clin (Engl Ed). 2020; 155(11):502-505. doi: 10.1016/j.medcle.2020.05.028.

[33] Cunningham M. Pathogenesis of group A streptococcal infections. Clin Microbiol Rev. 2000; 13(3):470-511. doi: 10.1128/cmr.13.3.470511.2000.

[34] Kanwal S., Vaitla P. Streptococcus Pyogenes. 2020 Aug 10. In StatPearls [Internet]. Treasure Island (FL): StatPearls Publishing; 2021.

[35] Khaddour K., Sikora A., Tahir N., Nepomuceno D., Huang T. Case Report: The importance of novel coronavirus disease (Covid-19) and co-infection with other respiratory pathogens in the current pandemic. Am J Trop Med Hyg. 2020; 102(6):1208-1209. doi: 10.4269/ajtmh.200266.

[36] Asif M., Alvi I., Rehman S. Insight into Acinetobacter baumannii: pathogenesis, global resistance, mechanisms of resistance, treatment options, and alternative modalities. Infect Drug Resist. 2018; 21(11):1249-1260. doi: 10.2147/IDR.S166750.

[37] Durán-Manuel E., Cruz-Cruz C., Ibáñez-Cervantes G., BravataAlcantará J., Sosa-Hernández O., Delgado-Balbuena L., et al. Clonal dispersion of Acinetobacter baumannii in an intensive care unit designed to patients COVID-19. J Infect Dev Ctries. 2021; 15(1):5868. doi: $10.3855 /$ jidc. 13545 .

[38] Sharifipour E., Shams S., Esmkhani M., Khodadadi J., FotouhiArdakani R., Koohpaei A., et al. Evaluation of bacterial co-infections of the respiratory tract in Covid-19 patients admitted to ICU. BMC Infect Dis. 2020; 20(1):646. doi: 10.1186/s12879-020-05374-z.

[39] Dissanayake T.K., Yan B., Ng A. C.-K., Zhao H., Chan G., Yip C.C.Y., et al. Differential role of sphingomyelin in influenza virus, rhinovirus and SARS-CoV-2 infection of Calu-3 cells. J Gen Virol. 2021;102:001593.DOI 10.1099/jgv.0.001593

[40] Aizaki H., Morikawa K., Fukasawa M., Hara H., Inoue Y., Tani H., et al. Critical role of virion-associated cholesterol and sphingolipid in hepatitis C virus infection. $J$ Virol. 2008; 82(12):5715-24. doi: 10.1128/JVI.02530-07.

[41] Miller M., Adhikary S., Kolokoltsov A., Davey R. Ebolavirus requires acid sphingomyelinase activity and plasma membrane sphingomyelin for infection. $J$ Virol. 2012; 86:7473-7483.

[42] Otsuki N., Sakata M., Saito K., Okamoto K., Mori Y., Hanada K., et al. Both sphingomyelin and cholesterol in the host cell membrane are essential for Rubella virus entry. J Virol. 2017; 92(1):e01130-17. doi: 10.1128/JVI.01130-17.

[43] Pastenkos G., Miller L., Pritchard M., Nicola V. Role of sphingomyelin in Alpha herpesvirus entry. J Virol. 2019; 93(5):e01547-18. doi: 10.1128/JVI.01547-18

[44] Shen B., Yi X., Sun Y., Bi X., Du J., Zhang C., et al. et al., Proteomic and metabolomic characterization of covid-19 Patient Sera. Cell. 2020: 182:59-72. DOI: https://doi.org/10.1016/j.cell.2020.05.032.

[45] Carpinteiro A., Gripp B., Hoffmann M., Pöhlmann S., Hoertel N. Edwards M.J., et al. Inhibition of acid sphingomyelinase by ambroxol prevents SARS-CoV-2 entry into epithelial cells. J Biol Chem. 2021; 296:100701. doi: 10.1016/j.jbc.2021.100701.

[46] Pemán J., Ruiz-Gaitán A., García-Vidal C., Salavert M., Ramírez P., Puchades F., et al. Fungal co-infection in covid-19 patients: Should we be concerned? Rev Iberoam Micol. 2020; 37(2):41-46. doi: 10.1016/j.riam.2020.07.001.

[47] Marshall J., Murthy S., Diaz J. WHO Working Group on the Clinical Characterization and management of Covid-19 infection. Fungal infections should be part of the core outcome set for COVID-19 Authors' reply. Lancet Infect Dis. 2020; S1473-3099(20)30681-2. doi: 10.1016/S1473-3099(20)30681-2.

[48] Song G., Liang G., Liu W. Fungal co-infections associated with global COVID-19 pandemic: A clinical and diagnostic perspective from China. Mycopathologia. 2020; 185(4):599-606. doi: 10.1007/s11046020-00462-9.

[49] Garcia-Vidal C., Sanjuan G., Moreno-García E., Puerta-Alcalde P., Garcia-Pouton N., Chumbita M., et al. Incidence of co-infections and superinfections in hospitalized patients with COVID-19: a retrospective cohort study. Clin Microbiol Infect. 2021; 27(1):83-88. doi: 10.1016/j.cmi.2020.07.041.

[50] Chen X., Liao B., Cheng L., Peng X., Xu X., Li Y., et al. The microbial coinfection in COVID-19. Appl Microbiol Biotechnol. 2020; 104(18):7777-7785. doi:10.1007/s00253-020-10814-6

[51] Lai C., Yu W. COVID-19 associated with pulmonary aspergillosis: A literature review. J Microbiol Immunol Infect. 2021; 54(1):46-53. doi: 10.1016/j.jmii.2020.09.004

[52] Koehler P., Bassetti M., Chakrabarti A., Chen S.C.A., Colombo A.L., Hoenigl M., et al. Defining and managing COVID-19-associated pulmonary aspergillosis: the 2020 ECMM/ISHAM consensus criteria for research and clinical guidance. Lancet Infect Dis. 2021; 21(6):e149 e162. doi: 10.1016/S1473-3099(20)30847-1.

[53] van Arkel A., Rijpstra T., Belderbos H., van Wijngaarden P., Verweij P., Bentvelsen R. COVID-19-associated Pulmonary Aspergillosis. Am J Respir Crit Care Med. 2020; 202(1):132-135. doi: 10.1164/rccm.202004-1038LE

[54] Sharma A., Hofmeyr A., Bansal A., Thakkar D., Lam L., Harrington Z., et al. COVID-19 associated pulmonary aspergillosis (CAPA): An Australian case report. Med Mycol Case Rep. 2021; 31:6-10. doi 10.1016/j.mmcr.2020.06.002.

[55] Imoto W., Himura H., Matsuo K., Kawata S., Kiritoshi A., Deguchi R., et al. COVID-19-associated pulmonary aspergillosis in a Japanese man: A case report. J Infect Chemother. 2021; 27(6):911-914. doi 10.1016/j.jiac.2021.02.026.

[56] Benedetti M., Alava K., Sagardia J., Cadena R., Laplume D., Capece P., et al. COVID-19 associated pulmonary aspergillosis in ICU patients: Report of five cases from Argentina. Med Mycol Case Rep. 2021; 31:24-28. doi: 10.1016/j.mmcr.2020.11.003.

[57] Prakash H., Chakrabarti A. Global epidemiology of mucormycosis. $J$ Fungi (Basel). 2019; 5(1):26. doi: 10.3390/jof5010026.

[58] Hunt E. Recognizing mucormycosis in an immunocompromised patient. JAAPA. 2020; 33(12):23-25. doi: 10.1097/01.JAA.0000721656.13462.67.

[59] Mehta S., Pandey A. Rhino-Orbital Mucormycosis Associated With COVID-19. Cureus. 2020; 12(9):e10726. doi: 10.7759/cureus. 10726.

[60] Sen M., Lahane S., Lahane T., Parekh R., Honavar S. Mucor in a Viral Land: A Tale of Two Pathogens. Indian J Ophthalmol. $2021 \mathrm{~F}$; 69(2):244-252. doi: 10.4103/ijo.IJO_3774_20.

[61] Mekonnen Z., Ashraf D., Jankowski T., Grob S., Vagefi M., Kersten R., et al. Acute invasive rhino-orbital mucormycosis in a patient with COVID-19-associated acute respiratory distress syndrome. Ophthalmic Plast Reconstr Surg. 2021; 37(2):e40-e80. doi 10.1097/IOP.0000000000001889.

[62] Revannavar S., Supriya P., Samaga L., Vineeth K. COVID-19 triggering mucormycosis in a susceptible patient: a new phenomenon in the developing world? BMJ Case Rep. 2021; 14(4):e241663. doi: 10.1136/bcr-2021-241663.

[63] Raut A., Huy N.T. Rising incidence of mucormycosis in patients with COVID-19: another challenge for India amidst the second wave? Lancet Respir Med. 2021; S2213-2600(21)00265-4. doi: 10.1016/S2213-2600(21)00265-4. Epub ahead of print.

[64] Singh A., Singh R., Joshi S., Misra A. Mucormycosis in COVID-19: A systematic review of cases reported worldwide and in India. Diabetes Metab Syndr. 2021; 15(4):102146. doi: 10.1016/j.dsx.2021.05.019.

[65] Sarkar S., Gokhale T., Choudhury S.S., Deb A.K. COVID-19 and orbital mucormycosis. Indian J Ophthalmol. 2021b; 69(4):1002-1004. doi: 10.4103/ijo.IJO_3763_20.

[66] Spellberg B., Ibrahim A. Recent advances in the treatment of mucormycosis. Curr Infect Dis Rep. 2010; 12(6):423-9. doi: 10.1007/s11908-010-0129-9.

[67] Goel P., Jain V., Sengar M., Mohta A., Das P., Bansal P. Gastrointestinal mucormycosis: a success story and appraisal of concepts. J Infect Public Health. 2013; 6(1):58-61. doi 10.1016/j.jiph.2012.08.004.

[68] Vediyappan G., Dumontet V., Pelissier F., d'Enfert C. Gymnemic acids inhibit hyphal growth and virulence in Candida albicans. PLoS One. 2013; 8(9):e74189. doi: 10.1371/journal.pone.0074189.

[69] Surapuram V., Setzer W., McFeeters R., McFeeters H. Antifungal activity of plant extracts against Aspergillus niger and Rhizopus stolonifer. Nat Prod Commun. 2014; 9(11):1603-5.

[70] Kim D., Quinn J., Pinsky B., Shah N., Brown I. Rates of Co-infection Between SARS-CoV-2 and Other Respiratory Pathogens. JAMA. 2020 323(20):2085-2086. doi:10.1001/jama.2020.6266.

[71] Ma L., Wang W., Le Grange J., Wang X., Du S., Li C., et al. Coinfection of SARS-CoV-2 and other respiratory pathogens. Infect Drug Resist. 2020; 13:3045-3053. doi: 10.2147/IDR.S267238.

[72] Burrel S., Hausfater P., Dres M., Pourcher V., Luyt C., Teyssou E., et al. Co-infection of SARS-CoV-2 with other respiratory viruses and performance of lower respiratory tract samples for the diagnosis of COVID-19. Int $J$ Infect Dis. 2021; 102:10-13. doi: 10.1016/j.ijid.2020.10.040.

[73] Chen N., Zhou M., Dong X., Qu J., Gong F., Han Y., et al. Epidemiological and clinical characteristics of 99 cases of 2019 novel coronavirus pneumonia in Wuhan, China: a descriptive study. Lancet 2020; 395(10223):507-513. doi: 10.1016/S0140-6736(20)30211-7.

[74] Cataldo M., Tetaj N., Selleri M., Marchioni L., Capone A., Caraffa E., et al. Incidence of bacterial and fungal bloodstream infections in COVID-19 patients in intensive care: An alarming "collateral effect". J Glob Antimicrob Resist. 2020; 23:290-291 doi: 10.1016/j.jgar.2020.10.004. 
[75] Moore S., Wilde A., Song M., Bohn B., Patross C., Denham B., et al. A patient with Escherichia coli bacteremia and covid-19 co-infection: A case report for the Louisville covid-19 epidemiology study," The University of Louisville Journal of Respiratory Infections. 2020; 1(4):15. DOI: $10.18297 /$ jri/vol4/iss $1 / 15$.

[76] Arcari G., Raponi G., Sacco F., Bibbolino G., Di Lella F., Alessandri F., et al. Klebsiella pneumoniae infections in COVID-19 patients: a 2month retrospective analysis in an Italian hospital. Int J Antimicrob Agents. 2021; 57(1):106245. doi: 10.1016/j.ijantimicag.2020.106245.

[77] Cheng L., Chau S., Tso E., Tsang S., Li I., Wong B., et al. Bacterial coinfections and antibiotic prescribing practice in adults with COVID-19: experience from a single hospital cluster. Ther Adv Infect Dis. 2020; 7:2049936120978095. doi: 10.1177/2049936120978095.

[78] Ramos-Martínez A., Fernández-Cruz A., Domínguez F., Forteza A., Cobo M., Sánchez-Romero I., et al. Hospital-acquired infective endocarditis during covid-19 pandemic. Infection Prevention in Practice. 2020; 2(3):100080. doi: 10.1016/j.infpip.2020.100080.

[79] Mahmoudi H. Bacterial co-infections and antibiotic resistance in patients with COVID-19. GMS Hyg Infect Control. 2020; 15:Doc35. doi: $10.3205 /$ dgkh000370.

[80] Michael C., Dominey-Howes D., Labbate M. The antimicrobial resistance crisis: causes, consequences, and management. Front Public Health. 2014; 2:145. doi: 10.3389/fpubh.2014.00145.

[81] O'Neill J. Antimicrobial Resistance: Tackling a crisis for the health and wealth of nations. The Review on Antimicrobial Resistance, Wellcome Trust Dec. 2014.

[82] Lucien M., Canarie M., Kilgore P., Jean-Denis G., Fénélon N., Pierre M., et al. Antibiotics and antimicrobial resistance in the COVID-19 era: Perspective from resource-limited settings. Int J Infect Dis. 2021; 104:250-254. doi: 10.1016/j.ijid.2020.12.087.

[83] Perez S., Innes G., Walters M., Mehr J., Arias J., Greeley R., Chew D. Increase in hospital-acquired carbapenem-resistant Acinetobacter baumannii infection and colonization in an acute care hospital during a surge in Covid-19 admissions- New Jersey, Feb-July 2020. Morb Mortal Wkly Rep. 2020; 69(48):1827-1831. doi: 10.15585/mmwr.mm6948e1.

[84] Randall M., Minahan T., Mesisca M., Gnass S. Nosocomial methicillin-resistant Staphylococcus aureus bacteremia in incarcerated patients with severe COVID-19 infection. Am J Infect Control. 2020; 48(12):1568-1569. doi: 10.1016/j.ajic.2020.09.005.

[85] Gottesman T., Fedorowsky R., Yerushalmi R., Lellouche J., Nutman A. An outbreak of carbapenem-resistant Acinetobacter baumannii in a COVID-19 dedicated hospital. Infection Prevention in Practice. 2021; 3(1):100113. doi: 10.1016/j.infpip.2021.100113.

[86] Lu J., Guo J. Disinfection spreads antimicrobial resistance. Science. 2021; 371(6528):474. doi: 10.1126/science.abg4380.

[87] Mc Carlie S., Boucher C., Bragg R. Molecular basis of bacterial disinfectant resistance. Drug Resist Updat. 2020; 48:100672. doi: 10.1016/j.drup.2019.100672.

[88] Pittet D., Peters A., Tartari E. Enterococcus faecium tolerance to isopropanol: from good science to misinformation. Lancet Infect Dis. 2018; 18(10):1065-1066. doi: 10.1016/S1473-3099(18)30542-5.

[89] Mitsuboshi S., Tsugita M. Impact of alcohol-based hand sanitizers, antibiotic consumption, and other measures on detection rates of antibiotic-resistant bacteria in rural Japanese hospitals. J Infect Chemother. 2019; 25(3):225-228. doi: 10.1016/j.jiac.2018.08.013.

[90] Prasad A., Muthamilarasan M., Prasad M. Synergistic antiviral effects against SARS-CoV-2 by plant-based molecules. Plant Cell Rep. 2020; 39(9):1109-1114. doi: 10.1007/s00299-020-02560-w.

[91] Habermann E., Friedenthal R. Septic arthritis associated with avascular necrosis of the femoral head. Clin. Orthop. Relat. Res. 1978; 134:325331. 